\title{
Increased Lipolysis and Its Consequences on Gluconeogenesis in Non-insulin-dependent Diabetes Mellitus
}

\author{
Nurjahan Nurjhan, Agostino Consoli, and John Gerich \\ Clinical Research Center, Departments of Medicine and Physiology, \\ University of Pittsburgh School of Medicine, Pittsburgh, Pennsylvania 15261
}

\begin{abstract}
The present studies were undertaken to determine whether lipolysis was increased in non-insulin-dependent diabetes mellitus (NIDDM) and, if so, to assess the influence of increased glycerol availability on its conversion to glucose and its contribution to the increased gluconeogenesis found in this condition. For this purpose, we infused nine subjects with NIDDM and 16 age-, weight-matched nondiabetic volunteers with $\left[2-{ }^{3} \mathrm{H}\right]$ glucose and $\left[\mathrm{U}^{14} \mathrm{C}\right]$ glycerol and measured their rates of glucose and glycerol appearance in plasma and their rates of glycerol incorporation into plasma glucose. The rate of glycerol appearance, an index of lipolysis, was increased 1.5-fold in NIDDM subjects $(2.85 \pm 0.16$ vs. $1.62 \pm 0.08 \mu \mathrm{mol} / \mathrm{kg}$ per $\mathrm{min}, P$ $<\mathbf{0 . 0 0 1})$. Glycerol incorporation into plasma glucose was increased threefold in NIDDM subjects $(1.13 \pm 1.10$ vs. $0.36 \pm 0.02 \mu \mathrm{mol} / \mathrm{kg}$ per $\mathrm{min}, P<0.01)$ and accounted for twice as much of hepatic glucose output $(6.0 \pm 0.5$ vs. $3.0 \pm 0.2 \%, P$ $<0.001)$. Moreover, the percent of glycerol turnover used for gluconeogenesis $(77 \pm 6$ vs. $44 \pm 2, P<0.001)$ was increased in NIDDM subjects and, for a given plasma glycerol concentration, glycerol gluconeogenesis was increased more than twofold. The only experimental variable significantly correlated with the increased glycerol gluconeogenesis after taking glycerol availability into consideration was the plasma free fatty acid concentration $(r=0.80, P<0.01)$. We, therefore, conclude that lipolysis is increased in NIDDM and, although more glycerol is thus available, increased activity of the intrahepatic pathway for conversion of glycerol into glucose, due at least in part to increased plasma free fatty acids, is the predominant mechanism responsible for enhanced glycerol gluconeogenesis. Finally, although gluconeogenesis from glycerol in NIDDM is comparable to that of alanine and about one-fourth that of lactate in terms of overall flux into glucose, glycerol is probably the most important gluconeogenic precursor in NIDDM in terms of adding new carbons to the glucose pool. (J. Clin. Invest. 1992. 89:169-175.) Key words: gluconeogenesis • glycerol - lipolysis
\end{abstract}

\section{Introduction}

Circulating glycerol originates primarily from adipose tissue as a result of the breakdown of stored triglycerides $(1,2)$. In humans, most of the glycerol undergoes either oxidation or con-

Address correspondence and reprint requests to John E. Gerich, M.D., Clinical Research Center, 3488 Presbyterian-University Hospital, Pittsburgh, PA 15261.

Received for publication 16 October 1990 and in revised form 28 August 1991.

J. Clin. Invest.

(c) The American Society for Clinical Investigation, Inc.

0021-9738/92/01/0169/07 \$2.00

Volume 89, January 1992, 169-175 version to glucose (2-4). Although $\sim 50 \%$ of the glycerol that is released into plasma in the postabsorptive state is converted to glucose (3-5), glycerol is normally considered a minor gluconeogenic substrate since it accounts for only $\sim 3 \%$ of overall hepatic glucose output and $10 \%$ of overall gluconeogenesis (3, 4). After a prolonged fast, however, lipolysis greatly increases and the proportion of glycerol turnover used for gluconeogenesis also increases so that glycerol can account for up to $60 \%$ of overall hepatic glucose output (3).

In non-insulin-dependent diabetes mellitus (NIDDM), ${ }^{1}$ overall gluconeogenesis is increased (6), and recently enhanced conversion of both lactate and alanine to glucose has been reported (7). The role of glycerol as a gluconeogenic precursor in this condition has yet to be determined. Glycerol is of particular interest because, in contrast to lactate and alanine most of whose carbons originate directly from plasma glucose $(8,9)$, essentially all of glycerol carbon incorporated into plasma glucose represents addition of new carbons to the glucose pool (2).

Another consideration is that glycerol availability as a gluconeogenic precursor may be increased in NIDDM. Most patients with NIDDM have an expanded adipose tissue mass and their adipose tissue is resistant to insulin (10). One would, therefore, expect that there may be enhanced lipolysis in this condition and that the resultant increased availability of glycerol would augment gluconeogenesis. Moreover, enhanced availability of FFA and their subsequent oxidation in liver could also increase gluconeogenesis (11).

Nevertheless, although obesity is associated with increased lipolysis (3), it remains to be established that lipolysis is increased in NIDDM. Plasma FFA turnover in individuals with NIDDM has not been found to be greater than that in weightmatched nondiabetic individuals (12-16). Furthermore, there is evidence that the increased plasma FFA concentrations in NIDDM may be due to reduced reesterification (12). Finally, in vitro studies indicate that the antilipolytic effect of insulin on adipocytes from NIDDM subjects is not impaired (17-19).

Despite these observations, there still might be increased lipolysis in NIDDM. The failure to demonstrate increased lipolysis by adipocytes from NIDDM individuals in vitro could merely mean that in vivo factors are essential. Moreover, FFA turnover may not necessarily be a reliable indicator of lipolysis in NIDDM. FFA can be reesterified within adipose tissue after lipolysis (20). The hyperglycemia and hyperinsulinemia characteristic of NIDDM could promote reesterification of FFA within the adipocyte so that some FFA liberated from triglyceride do not enter the circulation (21). Glycerol liberated within the adipocyte as a result of lipolysis cannot be reincorporated into triglyceride because adipose tissue lacks glycerokinase (22). Release of glycerol into plasma should therefore be a more reliable index of lipolysis than release of FFA.

1. Abbreviation used in this paper: NIDDM, non-insulin-dependent diabetes mellitus. 
The present experiments were undertaken with three aims in mind: $(a)$ to determine whether there is increased lipolysis in NIDDM (as reflected by the rate of glycerol appearance in plasma); (b) to quantitate the contribution of glycerol gluconeogenesis to overall hepatic glucose output in NIDDM; and (c) using glycerol as a model, to assess the relative importance of alterations in substrate availability and intrahepatic pathways for the increased gluconeogenesis found in this condition.

\section{Methods}

Subjects. Informed, written consent was obtained from nine subjects with NIDDM and from 16 nondiabetic subjects matched for age, gender, and body mass index. Body mass index ranged from 24 to 28 and 24 to 29 in the female and male nondiabetic subjects and from 22 to 30 and 24 to 29 in the female and male NIDDM subjects (Table I). None of the diabetic subjects had been treated with insulin; those being treated with sulfonylureas had their medication discontinued $10 \mathrm{~d}$ before the study. All subjects had normal renal and hepatic function and each consumed a weight-maintaining diet containing at least $200 \mathrm{~g}$ carbohydrate for $3 \mathrm{~d}$ before the study.

Protocol. Subjects were admitted to the University of Pittsburgh General Clinical Research Center the evening before the experiments between 5:00 and 7:00 p.m., were given a standard meal $(10 \mathrm{cal} / \mathrm{kg}$; $50 \%$ carbohydrate, $35 \%$ fat, and $15 \%$ protein) and were studied the next morning after a $12-14$-h fast.

At 4:00 a.m., primed continuous infusions of $\left[\mathrm{U}^{14} \mathrm{C}\right]$ glycerol $(30$ $\mu \mathrm{Ci}, 0.30 \mu \mathrm{Ci} / \mathrm{min}$ ) (Research Products, Mount Prospect, IL) and [2- $\left.{ }^{3} \mathrm{H}\right]$ glucose $(20 \mu \mathrm{Ci}, 0.20 \mu \mathrm{Ci} / \mathrm{min}$, Amersham Corp., Arlington Heights, IL) were started through an antecubital vein. At 7:00 a.m. a dorsal hand vein was retrogradely cannulated and placed in a thermoregulated device maintained at $65^{\circ} \mathrm{C}$ for sampling of arterialized venous blood.

After allowing $4 \mathrm{~h}$ for isotopic equilibration, four blood samples were taken at 15-30-min intervals for determination of plasma substrate concentrations (glucose, glycerol, and FFA), and hormone (insulin and glucagon) concentrations, and specific activity of plasma $\left[{ }^{14} \mathrm{C}\right]-$ and $\left[{ }^{3} \mathrm{H}\right]$ glucose and plasma $\left[{ }^{14} \mathrm{C}\right]$ glycerol. In addition, after obtaining the above basal samples, five of the nondiabetic subjects were infused with glycerol at rates of $0.55,1.18$, and $1.65 \mu \mathrm{mol} / \mathrm{kg}$ per min in ascending order (each for $90 \mathrm{~min}$ ) to increase plasma glycerol concentrations into the range found in our NIDDM subjects. Blood was sampled for plasma glucose and glycerol concentrations and specific activities at 15-30-min intervals. All blood samples were placed immediately in a $4^{\circ} \mathrm{C}$ ice bath to prevent in vitro lipolysis of endogenous triglycerides. Plasma was separated by centrifugation at $4^{\circ} \mathrm{C}$ and frozen at $-20^{\circ} \mathrm{C}$ until the time of analysis.

Analytical procedures. Plasma glucose was determined with a glucose analyzer (Yellow Springs Instrument Co., Yellow Springs, $\mathrm{OH}$ ). Plasma glycerol was determined by a standard microfluorometric assay (23). Plasma FFA concentrations were determined by an enzymatic method (24). Plasma insulin and glucagon were determined by radioimmunoassays with an interassay variability of 3 and $4 \%$, respectively $(25$, 26). Plasma $\left[{ }^{14} \mathrm{C}\right]$ - and $\left[{ }^{3} \mathrm{H}\right]$ glucose and plasma $\left[{ }^{14} \mathrm{C}\right]$ glycerol specific activities were determined by HPLC as described previously (4).

Calculations. Because experiments were performed under steadystate conditions, rates of glucose and glycerol turnover $\left(R_{t}\right)$ were determined by dividing the infusion rates of $\left[2-{ }^{3} \mathrm{H}\right]$ glucose and $\left[\mathrm{U}-{ }^{14} \mathrm{C}\right]-$ glycerol (disintegrations per minute per kilogram body weight per minute) by their respective steady-state specific activities (disintegrations per minute per micromole). The percentage of plasma glucose derived from glycerol was calculated from the ratio of $\left[{ }^{14} \mathrm{C}\right]$ glucose and $\left[{ }^{14} \mathrm{C}\right]-$ glycerol specific activities (4). The rate of glycerol conversion to glucose was calculated by multiplying the percent of glucose derived from glycerol by the glucose $R_{\mathrm{t}}$. The metabolic clearance rate of glycerol was calculated by dividing glycerol $R_{\mathrm{t}}$ by plasma glycerol concentration. The percent of glycerol turnover incorporated into plasma glucose was calculated by dividing the rate of glycerol conversion to glucose by glycerol $R_{\mathrm{t}}$.

The body fat mass was determined by bioelectric impedance (Body Composition Analyzer; RJL Systems, Detroit, MI) (27) and the percent of body weight due to fat was calculated dividing body fat mass by body weight. This approach has been reported to have an error $<5 \%(28)$.

Statistical analysis. Data are given as mean \pm SEM. Unless otherwise stated, statistical evaluation was performed using two-tailed Student's $t$ test and least squares linear regression analysis.

\section{Results}

Plasma glucose, glycerol, free fatty acid, insulin, and glucagon concentrations (Table I). Plasma glucose, glycerol, FFA, insulin and glucagon concentrations were all significantly greater in the NIDDM subjects (Table I). Plasma insulin and glucagon were not affected by the glycerol infusion in the five nondiabetic subjects $(40 \pm 1 \mathrm{pM}$ and $221 \pm 40 \mathrm{ng} /$ liter, respectively, before glycerol infusion versus $40 \pm 2 \mathrm{pM}$ and $205 \pm 35 \mathrm{ng} /$ liter, respectively, during the highest glycerol infusion).

Plasma $\left[2-{ }^{3} \mathrm{H},{ }^{14} \mathrm{C}\right]$ glucose and $\left[{ }^{14} \mathrm{C}\right]$ glycerol specific activities (Table II). The data given in Table II indicate that in the basal (postabsorptive) experiments, isotopic steady state had been approximated for $\left[2-{ }^{3} \mathrm{H}\right]$ glucose, $\left[{ }^{14} \mathrm{C}\right]$ glucose, and $\left[{ }^{14} \mathrm{C}\right]$ glycerol in both groups of subjects $(P=$ NS between time points in each group by ANOVA). Similarly, isotopic steady state was closely approached during the last $30 \mathrm{~min}$ of each 90 -min glycerol infusion in the five nondiabetic subjects in whom these experiments were conducted.

Plasma glucose and glycerol turnover (Table I, Figs. 1 and 2). As expected, plasma glucose turnover was greater in the NIDDM subjects $(18.3 \pm 0.4 \mu \mathrm{mol} / \mathrm{kg}$ per min) than in the nondiabetic subjects $(11.9 \pm 0.3 \mu \mathrm{mol} / \mathrm{kg}$ per min, $P<0.001)$. Plasma glycerol turnover was also significantly greater in the NIDDM subjects $(2.85 \pm 0.16$ vs. $1.62 \pm 0.08 \mu \mathrm{mol} / \mathrm{kg}$ per min, $P<0.001)$. The NIDDM and nondiabetic subjects had comparable fat masses $(17.8 \pm 1.3$ and $17.7 \pm 1.1 \mathrm{~kg}$, respectively; range, $13-28$ in the nondiabetic subjects and 12-26 in the NIDDM subjects). Consequently, the NIDDM subjects also

Table I. Clinical and Metabolic Characteristics of Subjects Studied

\begin{tabular}{lccc}
\hline & $\begin{array}{c}\text { Nondiabetic } \\
\text { subjects }\end{array}$ & $\begin{array}{c}\text { Diabetic } \\
\text { subjects }\end{array}$ & $P$ \\
\hline Age $(y r)$ & $51 \pm 2$ & $54 \pm 2$ & $\mathrm{NS}$ \\
Gender & $10 \mathrm{M}, 6 \mathrm{~F}$ & $6 \mathrm{M}, 3 \mathrm{~F}$ & $\mathrm{NS}$ \\
Body mass index $\left(\mathrm{kg} / \mathrm{M}^{2}\right)$ & $25.7 \pm 0.7$ & $26.5 \pm 0.9$ & $\mathrm{NS}$ \\
Body fat mass $(\mathrm{kg})$ & $17.7 \pm 1.1$ & $17.8 \pm 1.3$ & $\mathrm{NS}$ \\
Body fat mass $(\%$ of $w \mathrm{t})$ & $23.2 \pm 1.3$ & $23.8 \pm 2.5$ & $\mathrm{NS}$ \\
Plasma glucose $(\mathrm{mM})$ & $5.2 \pm 0.1$ & $10.9 \pm 0.4$ & $<0.001$ \\
Plasma insulin $(p M)$ & $40 \pm 4$ & $76 \pm 8$ & $<0.001$ \\
Plasma glucagon $(\mathrm{ng} / \mathrm{liter})$ & $179 \pm 18$ & $238 \pm 23$ & $<0.02$ \\
Plasma glycerol $(\mu M)$ & $65 \pm 3$ & $95 \pm 9$ & $<0.01$ \\
Plasma FFA $(\mu M)$ & $400 \pm 22$ & $516 \pm 29$ & $<0.02$ \\
Glucose turnover & & & \\
$\quad(\mu \mathrm{mol} / \mathrm{kg} / \mathrm{min})$ & $11.9 \pm 0.3$ & $18.3 \pm 0.4$ & $<0.001$ \\
Glycerol turnover & & & \\
$\quad(\mu \mathrm{mol} / \mathrm{kg} / \mathrm{min})$ & $1.62 \pm 0.08$ & $2.85 \pm 0.16$ & $<0.001$ \\
Glycerol clearance & & & \\
$\quad(\mathrm{ml} / \mathrm{kg} / \mathrm{min})$ & $25.5 \pm 1.0$ & $31.3 \pm 1.9$ & $<0.007$ \\
\end{tabular}



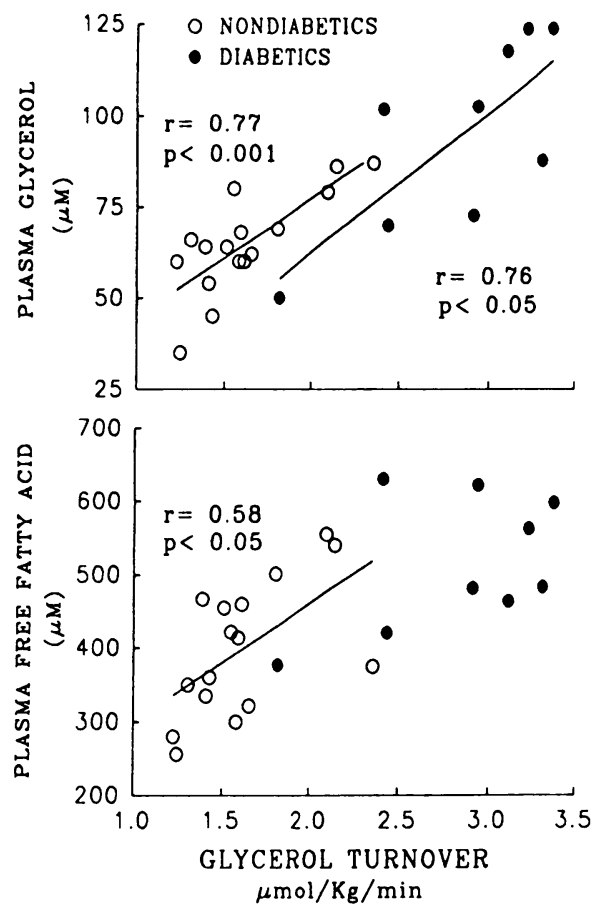

Figure 1. Relationship between plasma glycerol turnover and plasma glycerol and FFA concentrations.

had greater glycerol turnover $(13.0 \pm 1.3$ vs. $7.2 \pm 0.4 \mu \mathrm{mol} / \mathrm{kg}$ per min, $P<0.001)$ expressed per kilogram body fat. As shown in Fig. 1, there was a significant positive correlation between plasma glycerol turnover and both plasma glycerol $(r=0.77, P$ $<0.001)$ and plasma FFA $(r=0.58, P<0.05)$ concentrations in the nondiabetic subjects; in the NIDDM subjects plasma glycerol concentration $(r=0.76, P<0.05)$ but not plasma FFA concentration $(r=0.46, P>0.1)$ was significantly correlated with glycerol turnover. As shown in Fig. 2, there was a signifcant correlation between fat mass (kilograms) and glycerol turnover (micromoles per minute) in the nondiabetic subjects $(r$ $=0.64, P<0.01)$ but not in the NIDDM subjects $(r=0.13, P$ $>0.5$ ).

Glycerol incorporation into glucose (Figs. 3-5). The rate of plasma glycerol conversion to glucose was threefold greater in the NIDDM subjects $(1.13 \pm 0.10$ vs. $0.36 \pm 0.02 \mu \mathrm{mol} / \mathrm{kg}$ per

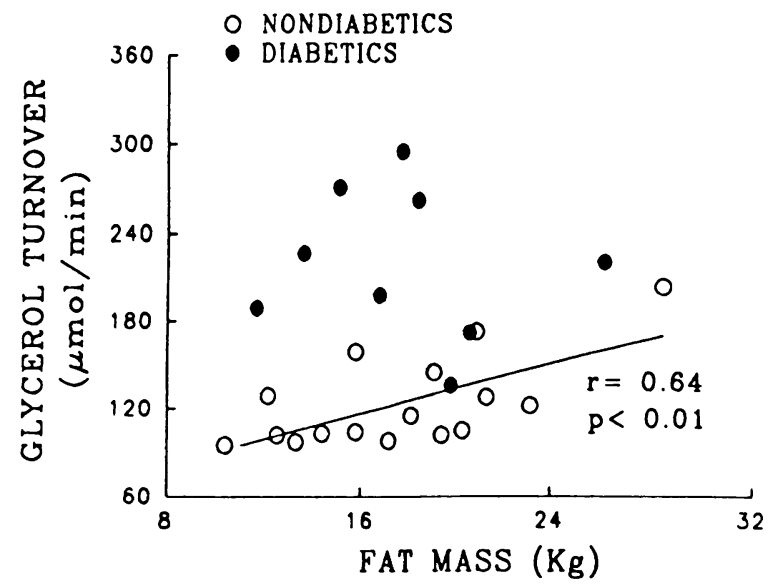

Figure 2. Relationship between plasma glycerol turnover and fat mass.

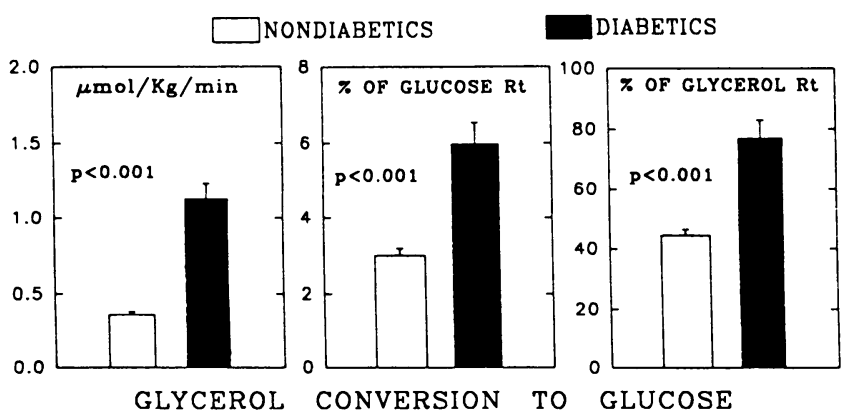

Figure 3. Rate of plasma glycerol conversion to plasma glucose and proportion of glucose appearance and glycerol turnover accounted for by glycerol gluconeogenesis.

min, in the nondiabetic subjects, $P<0.0001$ ) (Fig. 3). As shown in Fig. 4, there was a significant positive correlation between the rate of glycerol conversion to glucose and the plasma glycerol concentration in each group $(r=0.80$ and $r$ $=0.92$ in nondiabetic and NIDDM subjects respectively, both $P<0.001$ ). However, at comparable plasma glycerol concentrations, there was greater conversion of glycerol into glucose in the NIDDM subjects. Thus, the nondiabetic subjects who were infused with glycerol to increase their plasma glycerol concentrations into the range found in the NIDDM subjects $(\sim 100-$ $120 \mu \mathrm{M})$ still had lower rates of glycerol conversion to glucose than the NIDDM subjects ( $\sim 0.5 \mathrm{vs.} \sim 1.2 \mu \mathrm{mol} / \mathrm{kg}$ per min). As shown in Fig. 5, in both groups there was a significant correlation between plasma FFA concentration and glycerol gluconeogenesis $(r=0.64$ and 0.71 in nondiabetic and NIDDM subjects, respectively, both $P<0.03$ ). However, for a given plasma FFA concentration, NIDDM subjects had greater gluconeogenesis.

Contribution of glycerol gluconeogenesis to glucose and glycerol turnover (Fig. 3). Despite the fact that glucose turnover was greater in the NIDDM subjects, glycerol gluconeogenesis accounted for twice as much of hepatic glucose output in the NIDDM subjects $(6.0 \pm 0.5 \%$ vs. $3.0 \pm 0.2 \%$, in the nondiabetic subjects, $P<0.001$ ). Moreover, conversion of glycerol into glucose accounted for a greater proportion of glycerol turnover in the NIDDM subjects $(77 \pm 6$ vs. $44 \pm 2 \%$ in the nondiabetic subjects, $P<0.001$ ). This enhanced proportion of glycerol turnover used for gluconeogenesis could not be the mere result of the increased plasma glycerol concentrations in the NIDDM

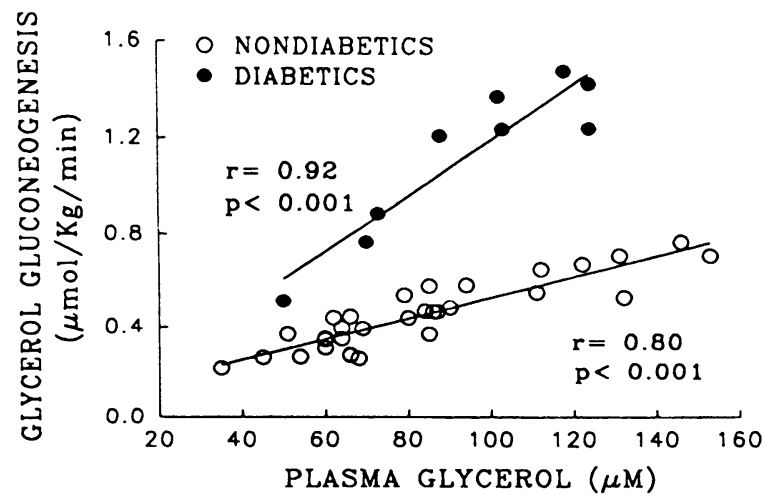

Figure 4. Relationship between plasma glycerol concentrations and rate of glycerol conversion to plasma glucose. 


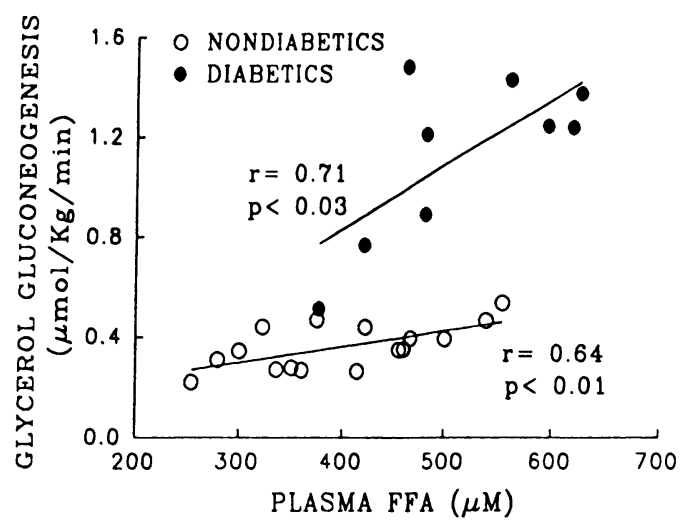

Figure 5. Relationship between plasma FFA concentrations and plasma glycerol conversion to glucose.

subjects because the percent of glycerol turnover accounted for by gluconeogenesis was still $<50 \%$ (range $40-44$ ) in the nondiabetic subjects who were infused with glycerol to increase their plasma glycerol concentrations above the mean value of the NIDDM subjects. The metabolic clearance rate of glycerol was greater in the NIDDM subjects than that of the nondiabetic subjects $(31 \pm 2$ vs. $25 \pm 1 \mathrm{ml} / \mathrm{kg}$ per $\min , P<0.01)$ and was significantly correlated with their glycerol gluconeogenesis $(r$ $=0.75, P<0.02)$; no such correlation was found in the nondiabetic subjects.

\section{Discussion}

The present studies were undertaken to determine whether there was increased lipolysis in individuals with non-insulindependent diabetes mellitus and, if so, to assess the influence of increased glycerol availability on its conversion to glucose and its contribution to the increased gluconeogenesis found in this condition.
To assess lipolysis, we used the appearance rate of glycerol in plasma because this was thought to be a more reliable index of lipolysis than that of FFA. The rate of glycerol appearance in plasma was found to be $>1.5$ times greater in NIDDM subjects than in age-, gender-, weight-matched nondiabetic volunteers whether expressed per body weight $(2.85 \pm 0.16$ vs. $1.62 \pm 0.08$ $\mu \mathrm{mol} / \mathrm{kg}$ per min, $P<0.01)$ or per fat mass $(13.0 \pm 1.3 \mathrm{vs}$. $7.2 \pm 0.4 \mu \mathrm{mol} / \mathrm{kg}$ per min, $P<0.01)$. In the nondiabetic subjects, the rate of glycerol appearance (micromoles per minute) was significantly correlated with fat mass (kilograms), whereas no significant correlation was found in the NIDDM subjects.

These results thus indicate that in individuals with NIDDM, lipolysis is significantly increased irrespective of their fat mass. A recent preliminary report (29) in which glycerol turnover was used to assess lipolysis also found increased lipolysis in NIDDM. The failure of previous studies (12-16) to find evidence for increased lipolysis in NIDDM may relate to their use of FFA appearance in plasma as an index of lipolysis rather than that of glycerol.

In the present studies, there was a significant correlation between glycerol turnover and plasma glycerol concentration in the NIDDM subjects but not between glycerol turnover and plasma FFA concentration despite the fact that plasma FFA concentrations were significantly greater in the NIDDM subjects. Although this could have resulted from study of too few NIDDM subjects, these observations nevertheless suggest that plasma FFA concentration is not a reliable indicator of lipolysis in NIDDM. Conceivably in some NIDDM subjects, hyperglycemia along with hyperinsulinemia may have increased intraadipocyte FFA reesterification, whereas in other NIDDM subjects there may have been a defect in extraadipocyte reesterification (12) and that such situations could explain the lack of correlation between plasma FFA concentration in our NIDDM subjects and both their fat mass and rates of glycerol appearance.

Table II. Specific Activities of Plasma $\left[2-{ }^{3} \mathrm{H}\right]$ Glucose, $\left[{ }^{14} \mathrm{C}\right]$ Glucose, and $\left[{ }^{14} \mathrm{C}\right]$ Glycerol

\begin{tabular}{|c|c|c|c|c|c|c|}
\hline \multirow[b]{2}{*}{ Time } & \multicolumn{2}{|c|}{$\left[2-{ }^{3} \mathrm{H}\right]$ glucose specific activity } & \multicolumn{2}{|c|}{$\left[{ }^{14} \mathrm{C}\right]$ glucose specific activity } & \multicolumn{2}{|c|}{$\left[{ }^{14} \mathrm{C}\right]$ glycerol specific activity } \\
\hline & $\begin{array}{l}\text { Nondiabetic } \\
\text { subjects }\end{array}$ & $\begin{array}{l}\text { NIDDM } \\
\text { subjects }\end{array}$ & $\begin{array}{l}\text { Nondiabetic } \\
\text { subjects }\end{array}$ & $\begin{array}{l}\text { NIDDM } \\
\text { subjects }\end{array}$ & $\begin{array}{l}\text { Nondiabetic } \\
\text { subjects }\end{array}$ & $\begin{array}{l}\text { NIDDM } \\
\text { subjects }\end{array}$ \\
\hline & \multicolumn{6}{|c|}{$d p m / \mu m o l$} \\
\hline \multicolumn{7}{|l|}{ Basal studies } \\
\hline-60 & $430 \pm 29$ & $406 \pm 58$ & $413 \pm 24$ & $495 \pm 76$ & $6965 \pm 382$ & $4559 \pm 518$ \\
\hline-30 & $440 \pm 30$ & $400 \pm 48$ & $403 \pm 25$ & $504 \pm 75$ & $6666 \pm 512$ & $4480 \pm 530$ \\
\hline-15 & $408 \pm 27$ & $403 \pm 47$ & $403 \pm 25$ & $529 \pm 85$ & $6746 \pm 466$ & $4391 \pm 505$ \\
\hline 0 & $434 \pm 29$ & $415 \pm 49$ & $400 \pm 23$ & $547 \pm 84$ & $6728 \pm 488$ & $4445 \pm 493$ \\
\hline \multicolumn{7}{|c|}{ Glycerol infusion studies* } \\
\hline 60 & \multicolumn{2}{|c|}{$428 \pm 42$} & \multicolumn{2}{|c|}{$382 \pm 33$} & \multicolumn{2}{|c|}{$6019 \pm 1176$} \\
\hline 75 & \multicolumn{2}{|c|}{$445 \pm 47$} & \multicolumn{2}{|c|}{$389 \pm 34$} & \multicolumn{2}{|c|}{$5311 \pm 909$} \\
\hline 90 & \multicolumn{2}{|c|}{$423 \pm 35$} & \multicolumn{2}{|c|}{$399 \pm 32$} & \multicolumn{2}{|c|}{$5540 \pm 735$} \\
\hline 150 & \multicolumn{2}{|c|}{$450 \pm 30$} & \multicolumn{2}{|c|}{$408 \pm 31$} & \multicolumn{2}{|c|}{$5050 \pm 1182$} \\
\hline 165 & \multicolumn{2}{|c|}{$470 \pm 33$} & \multicolumn{2}{|c|}{$407 \pm 26$} & \multicolumn{2}{|c|}{$4746 \pm 916$} \\
\hline 180 & \multicolumn{2}{|c|}{$473 \pm 32$} & \multicolumn{2}{|c|}{$417 \pm 27$} & \multicolumn{2}{|c|}{$4495 \pm 617$} \\
\hline 240 & \multicolumn{2}{|c|}{$509 \pm 32$} & \multicolumn{2}{|c|}{$441 \pm 29$} & \multicolumn{2}{|c|}{$3359 \pm 499$} \\
\hline 255 & \multicolumn{2}{|c|}{$502 \pm 31$} & \multicolumn{2}{|c|}{$447 \pm 29$} & \multicolumn{2}{|c|}{$3584 \pm 565$} \\
\hline 270 & \multicolumn{2}{|c|}{$534 \pm 40$} & \multicolumn{2}{|c|}{$445 \pm 30$} & \multicolumn{2}{|c|}{$3579 \pm 572$} \\
\hline
\end{tabular}

* Glycerol was infused from 0 to $90 \mathrm{~min}$ at a rate of $0.55 \mu \mathrm{mol} / \mathrm{kg}$ per min, from 90 to $180 \mathrm{~min}$ at a rate of $1.18 \mu \mathrm{mol} / \mathrm{kg}$ per $\mathrm{min}$ and from 180 to 270 at a rate of $1.65 \mu \mathrm{mol} / \mathrm{kg}$ per $\mathrm{min}$ in five of the 16 nondiabetic subjects. 
The increased rates of glycerol appearance found in our NIDDM subjects were accompanied by a disproportionately increased rate of glycerol incorporation into plasma glucose $(1.13 \pm 0.10$ vs. $0.36 \pm 0.02 \mu \mathrm{mol} / \mathrm{kg}$ per min, $P<0.001)$. Glycerol conversion to plasma glucose was increased threefold in the NIDDM subjects, whereas their rates of glycerol appearance were increased only 1.5-fold. Thus, a greater proportion of glycerol turnover was used for gluconeogenesis in the NIDDM subjects than in the nondiabetic volunteers ( $77 \pm 6$ vs. $44 \pm 2 \%, P<0.05$ ). In a preliminary report (29), Puhakainen also found a greater proportion of glycerol turnover used for gluconeogenesis in NIDDM. These observations suggest that factors other than a mere increase in glycerol availability were responsible for the increased gluconeogenesis from glycerol in the NIDDM subjects.

It should be pointed out that because of intrahepatic lipolysis, intrahepatic $\left[{ }^{14} \mathrm{C}\right]$ glycerol specific activity would be expected to be lower than the intraarterial specific activity. Thus, the use of arterial plasma specific activity of the $\left[{ }^{14} \mathrm{C}\right]$ glycerol rather than its intrahepatic value would lead to an underestimation of glycerol incorporation into glucose in both groups studied. However, because lipolysis was significantly greater in NIDDM subjects, the intrahepatic specific activity of $\left[{ }^{14} \mathrm{C}\right]$ glycerol would also probably have been less in the diabetic subjects. Therefore, the underestimation of glycerol gluconeogenesis probably was greater in NIDDM subjects. Thus, our results most likely represent a conservative estimation of the overproduction of glucose from glycerol in NIDDM.

The relationship found between glycerol gluconeogenesis and plasma glycerol concentrations in the present study support the view that accelerated intrahepatic pathways rather than increased glycerol availability was the major factor responsible for increased glycerol gluconeogenesis found in the NIDDM subjects. In each group of subjects, there was a significant correlation between plasma glycerol concentration and gluconeogenesis from glycerol; however, at any given plasma glycerol concentration, there was greater gluconeogenesis from glycerol in the NIDDM subjects. Indeed, even when normal volunteers were infused with glycerol so as to increase their circulating glycerol concentrations above those found in the NIDDM subjects, the rates of glycerol gluconeogenesis in the nondiabetic subjects were still less than half those found in the NIDDM subjects. These observations suggest that the activity of the intrahepatic pathway for conversion of glycerol into glucose was increased in the NIDDM subjects.

There are several intrahepatic steps whose alteration in NIDDM could promote increased glycerol incorporation to glucose (30). Most prominent among these would be the phosphofructokinase-fructose 1,6-biphosphatase step. A reduction in the activity of phosphofructokinase and an increase in the activity of fructose 1,6-biphosphatase would promote glycerol being incorporated into glucose rather than its undergoing glycolysis or oxidation in the liver. FFA whose circulating levels were increased in our NIDDM subjects increase the activity of fructose 1,6-biphosphatase (31). Fructose $2,6-\mathrm{P}_{2}$ is a potent inhibitor of fructose 1,6-biphosphatase and a stimulator of the phosphofructokinase (32). The level of hepatic fructose $2,6-\mathrm{P}_{2}$ is reduced in diabetic animals (33) and is also reduced by glucagon (32) whose circulating levels were increased in our diabetic subjects. All of these factors have played a role in accelerating intrahepatic incorporation of glycerol in glucose in our NIDDM subjects.
An appreciation of the relative importance of the activity of the intrahepatic pathway and glycerol availability can be obtained from further analysis of the relationships between plasma glycerol concentrations and glycerol gluconeogenesis (Fig. 4). Glycerol availability as reflected by plasma glycerol concentrations was increased $\sim 45 \%$ in the NIDDM subjects, whereas both the slope $(0.012$ vs. 0.005$)$ of the regression line relating plasma glycerol to glycerol gluconeogenesis was increased in the NIDDM subjects $>200 \%$. This further suggests that accelerated intrahepatic conversion of glycerol to glucose was a more important factor for the increased glycerol gluconeogenesis than increased glycerol availability.

Recently, evidence for increased intrahepatic conversion of lactate to glucose has been reported in NIDDM (7). The mechanisms responsible for the increased activity of intrahepatic pathways for conversion of gluconeogenic precursors to glucose are unclear. In the present study, NIDDM subjects had increased plasma glucagon and FFA levels and were insulin resistant as indicated by their fasting hyperinsulinemia. Hyperglucagonemia (34), increased hepatic FFA oxidation (11), and hepatic insulin resistance (35) could all contribute to enhanced intrahepatic gluconeogenic precursor conversion to glucose. When we analyzed the increase in glycerol conversion to glucose in the NIDDM subjects above that expected from the increase in their plasma glycerol concentration (difference between observed rates versus those predicted from the regression equation for plasma glycerol versus glycerol gluconeogenesis in nondiabetic volunteers) by multiple linear regression in which differences in plasma insulin, glucagon, glucagon/insulin molar ratio, and plasma FFA concentration were independent variables, only the differences in plasma FFA concentrations were found to be a significant factor $(r=0.80, P<0.01)$. Moreover, using multiple linear regression, $86 \%$ of the variation in glycerol gluconeogenesis in the NIDDM subjects could be explained on the basis of plasma glycerol and FFA concentrations. Since there was no correlation between plasma FFA and glycerol turnover in the NIDDM subjects, this suggests that plasma FFA had an effect in accelerating glycerol gluconeogenesis independent of lipolysis. The most likely explanation for this effect would be enhanced hepatic FFA oxidation (11). Whether enhanced hepatic FFA oxidation also contributes to the increased lactate and alanine gluconeogenesis found in NIDDM (7) remains to be determined.

Glycerol is normally a minor gluconeogenic precursor usually accounting for $\sim 3 \%$ of overall hepatic glucose output and $\sim 10 \%$ of overall gluconeogenesis. In the present study, despite the fact that overall hepatic glucose output was increased in the NIDDM subjects, the proportion of hepatic glucose output derived from glycerol was about twofold greater in the NIDDM subjects than in the nondiabetic subjects $(6.0 \pm 0.5$ vs. $3.0 \pm 0.2 \%)$. This still represents a small proportion of overall hepatic glucose output. Nevertheless, in a preliminary report (29), Puhakainen found that glycerol gluconeogenesis accounted for $\sim 15 \%$ of overall hepatic glucose output in NIDDM.

It is worthy to note that a recent report (7) studying NIDDM subjects with rates of hepatic glucose output comparable to those in present study found alanine gluconeogenesis to be $\sim 1.2 \mu \mathrm{mol} / \mathrm{kg}$ per min. This is not appreciably different from that found in the present study for glycerol $(1.1 \mu \mathrm{mol} / \mathrm{kg}$ per min). Thus, in NIDDM gluconeogenesis from glycerol appears to be comparable to that of alanine, a substrate which has 
generally been considered an important gluconeogenic precursor. Moreover, since at least $50 \%$ of alanine carbons probably come directly from plasma glucose (9), glycerol could be viewed as more important in that its gluconeogenesis provides essentially all new carbons to the glucose pool.

Lactate is generally considered to be the most important gluconeogenesis precursor in man (1), accounting for $\sim 20 \%$ of hepatic glucose output and $60-80 \%$ of gluconeogenesis $(8$, 36). The study of Consoli et al. cited above (7), found lactate gluconeogenesis to be $\sim 4.3 \mu \mathrm{mol} / \mathrm{kg}$ per min in NIDDM subjects whose overall hepatic glucose output was comparable to those in the present study. Since up to $80 \%$ of lactate carbon has been reported to be derived from plasma glucose (8), the contribution of new carbon to the plasma glucose pool from $4.3 \mu \mathrm{mol} / \mathrm{kg}$ per min lactate gluconeogenesis could be as little as $0.9 \mu \mathrm{mol} / \mathrm{kg}$ per $\mathrm{min}$. Thus glycerol may be the most important gluconeogenic substrate in NIDDM in terms of adding new carbons to the plasma glucose pool. It should be pointed out, however, that this conclusion must be viewed in light of the fact that the inability to use the intrahepatic specific activity of all these precursors introduces some underestimation of their incorporation into glucose. Moreover, there are problems due to recycling of the carbon label. Thus, in the present studies, some $\left[{ }^{14} \mathrm{C}\right]$ carbons in glucose which came from the infused $\left[{ }^{14} \mathrm{C}\right]$ glycerol would be converted to lactate and alanine, and some of the resultant $\left[{ }^{14} \mathrm{C}\right]$ carbons in these gluconeogenic precursors would be reincorporated into glucose. A rough estimate of this process for lactate can be obtained using data in this report and the previously cited data of Consoli et al. (7). Assuming that $80 \%$ of lactate originates from glucose (8), lactate should have a steady-state specific activity $40 \%$ of that of glucose in disintegrations per minute per micromole because 2 mol of lactate originate from $1 \mathrm{~mol}$ of glucose. In the present study, glucose had a steady-state specific activity of $\sim 400$ $\mathrm{dpm} / \mu \mathrm{mol}$, and glycerol had a steady-state specific activity of $\sim 6,800 \mathrm{dpm} / \mu \mathrm{mol}$. Lactate should have had a steady-state specific activity of $\sim 160 \mathrm{dpm} / \mu \mathrm{mol}$. Multiplying the specific activities of lactate and glycerol by their rates of incorporation into glucose $-2.2 \mu \mathrm{mol} / \mathrm{kg}$ per min for glycerol and $8.6 \mu \mathrm{mol} /$ $\mathrm{kg}$ per min for lactate (7)-would provide an estimate of the relative inflow of $\left[{ }^{14} \mathrm{C}\right]$ into glucose directly from glycerol versus indirectly through lactate. The total disintegrations per minute per kilogram per minute incorporated into glucose from lactate and glycerol would be 16,336 . Of this, $1,376 \mathrm{dpm} / \mathrm{kg} /$ min $\sim 8 \%$ would represent $\left[{ }^{14} \mathrm{C}\right]$ recycled through lactate. Similar calculations for alanine indicate that $1 \%$ of the radioactivity came from recycled alanine. Nevertheless, it is a semantic question whether this $10 \%$ represents lactate and alanine gluconeogenesis or still glycerol gluconeogenesis because all $\left[{ }^{14} \mathrm{C}\right]$ carbons originally came from the infused $\left[{ }^{14} \mathrm{C}\right]$ glycerol.

In summary, the present studies demonstrate that lipolysis, as assessed by rates of glycerol appearance in plasma, is increased in NIDDM mellitus and that the conversion of glycerol to glucose in this condition is disproportionately enhanced relative to the increase in glycerol availability. The relationship found between plasma glycerol concentrations and glycerol conversion to glucose suggest that increased activity of intrahepatic pathways is more important than increased glycerol availability and that hepatic FFA oxidation may be a critical factor. Finally, although glycerol only accounted for $\sim 6 \%$ of overall hepatic glucose output in NIDDM subjects, it is probably as important a gluconeogenic precursor as lactate in the condition in terms of addition of new carbons to the glucose pool.

\section{Acknowledgments}

We thank the staff of General Clinical Research Center, Dawn Purdy, Carol Korbanic, Kathleen Greenawalt, and Dan Kirsch for their excellent technical help.

This publication was supported in part by funds received from grants from the Juvenile Diabetes Foundation International, the French National Institute of Health and Medical Research, the National Institutes of Health Division of Research Resources and the General Clinical Research Center (M501 RR-00056), and the Division of Diabetes, Endocrinology and Metabolic Diseases of the National Institute of Diabetes and Digestive and Kidney Diseases (DK-20411).

\section{References}

1. Hetenyi, G., G. Perez, and M. Vranic. 1983. Turnover and precursor product relationships of nonlipid metabolites. Physiol. Rev. 63:606-667.

2. Nurjhan, N., F. Kennedy, A. Consoli, C. Martin, J. Miles, and J. Gerich. 1988. Quantification of the glycolytic origin of plasma glycerol: implications for the use of the rate of appearance of plasma glycerol as an index of lipolysis in vivo. Metab. Clin. Exp. 37:386-389.

3. Bortz, W. M., P. Paul, A. C. Haff, and W. L. Holmes. 1972. Glycerol turnover and oxidation in man. J. Clin. Invest. 51:1537-1546.

4. Nurjhan, N., P. Campbell, F. Kennedy, J. Miles, and J. Gerich. 1986. Insulin dose-response characteristics for suppression of glycerol release and conversion to glucose in humans. Diabetes. 35:1326-1331.

5. Malmendier, C. L., C. Delcroix, and M. Berman. 1974. Interrelations in the oxidative metabolism of free fatty acids, glucose, and glycerol in normal and hyperlipemic patients. J. Clin. Invest. 54:461-476.

6. Consoli, A., N. Nurjhan, F. Capani, and J. Gerich. 1989. Predominant role of gluconeogenesis in increased hepatic glucose production in NIDDM. Diabetes. 38:550-557.

7. Consoli, A., N. Nurjhan, J. Reilly, D. Bier, and J. Gerich. 1990. Mechanism of increased gluconeogenesis in noninsulin-dependent diabetes mellitus: role of alterations in systemic, hepatic and muscle lactate and alanine metabolism. $J$. Clin. Invest. 86:2038-2045.

8. Kreisberg, R. A., L. F. Pennington, and B. R. Boshell. 1970. Lactate turnover and gluconeogenesis in normal and obese humans. Diabetes. 19:53-63.

9. Darmaun, D., D. E. Matthews, and D. M. Bier. 1988. Physiological hypercortisolemia increases proteolysis, glutamine, and alanine production. $\mathrm{Am}$. J. Physiol. 255:E366-E373.

10. Yki-Jarvinen, H., K. Kubo, J. Zawadski, S. Lillioja, A. Young, W. Abbott, and J. Foley. 1987. Dissociation of in vitro sensitivities of glucose transport and antilipolysis to insulin in NIDDM. Am. J. Physiol. 253:E300-E304.

11. Williamson, J., R. Kreisberg, and P. Felta. 1966. Mechanism for the stimulation of gluconeogenesis by fatty acids in perfused rat liver. Proc. Natl. Acad. Sci. USA. 56:247-254.

12. Taskinen, M. R., C. Bogardus, A. Kennedy, and B. V. Howard. 1985. Multiple disturbances of free fatty acid metabolism in noninsulin dependent diabetes. J. Clin. Invest. 76:637-644.

13. Groop, L., R. Bonadonna, S. DelPrato, K. Ratheiser, K. Zyck, E. Ferrannini, and $R$. DeFronzo. 1989. Glucose and free fatty acid metabolism in noninsulin dependent diabetes mellitus. J. Clin. Invest. 84:205-213.

14. Bolzano, K., F. Sandhofer, S. Sailer, and J. Braunsteiner. 1972. The effect of oral administration of sucrose on the turnover rate of plasma free fatty acids and on the esterification rate of plasma free fatty acids to plasma triglycerides in normal subjects, patients with primary endogenous hypertriglyceridemia, and patients with well controlled diabetes mellitus. Horm. Metab. Res. 4:439-446.

15. Csorba, T. R., I. Matsuda, and N. Kalant. 1966. Effects of insulin and diabetes on flux rates of plasma glucose and free fatty acids. Metab. Clin. Exp. 15:262-270.

16. Lewis, B., M. Mancini, M. Mattock, A. Chait, and R. Fraser. 1972. Plasma triglyceride and fatty acid metabolism in diabetes mellitus. Eur. J. Clin. Invest. 207:445-453.

17. Arner, P., J. Bolinder, P. Engfeldt, and J. Ostman. 1981. The antilipolytic effect of insulin in human adipose tissue in obesity, diabetes mellitus, hyperinsulinemia, and starvation. Metab. Clin. Exp. 30:753-760.

18. Lonroth, P., M. DiGirolamo, M. Krotkiewski, and U. Smith. 1983. Insulin binding and responsiveness in fat cells from patients with reduced glucose tolerance and type II diabetes. Diabetes. 32:748-754.

19. Foley, J. E., P. Thuillez, S. Lillioja, J. Zawadzki, and C. Bogardus. 1986. 
Insulin sensitivity in adipocytes from subjects with varying degrees of glucose tolerance. Am. J. Physiol. 251:E306-E310.

20. Shapiro, B., P. Chowers, and G. Rose. 1957. Fatty acid uptake and reesterification in adipose tissue. Biochim. Biophys. Acta. 23:115-120.

21. Shulman, G. I., P. E. Williams, J. E. Liljenquist, W. W. Lacy, V. Keller, and A. D. Cherrington. 1980. Effect of hyperglycemia independent of changes in insulin on glucagon on lipolysis in the conscious dog. Metab. Clin. Exp. 29:317320.

22. Vaughan, M. 1962. The production and release of glycerol by adipose tissue incubated in vitro. J. Biol. Chem. 237:3354-3358.

23. Wieland, O. 1974. Glycerol UV method. In Methods of Enzymatic Analysis. Vol. 3. U. Bergmeyer, editor. Academic Press, Inc., New York. 1404-1414.

24. Shimizu, S., Y. Tani, H. Yamada, M. Tabata, and T. Murochi. 1980 Enzymatic determination of serum free fatty acids: a colorimetric method. Anal. Biochem. 107:193-198.

25. Herbert, V., K. Lau, C. Gottlieb, and S. Bleicher. 1965. Coated charcoal immunoassay of insulin. J. Clin. Endocrinol. Metab. 25:1375-1384.

26. Faloona, G. R., and R. H. Unger. 1974. Glucagon. In Methods of Hormone Radioimmunoassay. B. M. Jaffe and H. R. Belivman, editors. Academic Press, Inc., New York. 317-330.

27. Guo, S., A. Roche, W. Chumlea, D. Miles, and R. Pohlman. 1987. Body composition predictions from bioelectric impedance. Human Biol. 59:221-233.

28. Houtkooper, L. B., T. G. Lohman, S. B. Going, and M. C. Hall. 1989.
Validity of bioelectric impedance for body composition assessment in children. Am. J. Physiol. 66:814-821.

29. Puhakainen, I. 1990. Contribution of glycerol to gluconeogenesis in NIDDM. Diabetes. 39(Suppl. 1):87A. (Abstr.)

30. Cherrington, A., and M. Vranic. 1986. Hormonal control of gluconeogenesis in vivo. In Hormonal Control of Gluconeogenesis. N. Kraus-Friedmann, editor. CRC Press, Inc., Boca Raton, FL. 15-37.

31. Carlson, C. W., R. C. Baxter, E. H. Ulm, and B. M. Pogell. 1973. Role of oleate in the regulation of "neutral" rabbit liver fructose 1,6-diphosphatase activity. J. Biol. Chem. 248:5555-5561.

32. Hers, H. G., and E. Van Schaftingen. 1982. Fructose 2,6 biphosphate 2 years after its discovery. Biochem. J. 206:1-12.

33. Neely, P., M. R. El-Maghrabi, S. J. Pilkis, and T. H. Clause. 1981. Effect of diabetes, insulin, starvation, and refeeding on the level of rat hepatic fructose 2,6 biphosphate. Diabetes. 30:1062-1064.

34. Unger, R. H., E. Aguilar Paradz, W. A. Meuller, and A. M. Eisentrant. 1970. Studies of alpha-cell function in normal and diabetic subjects. J. Clin. Invest. 49:837-845.

35. Campbell, P., L. Mandarino, and J. Gerich. 1988. Quantification of the relative impairment in actions of insulin on hepatic glucose production and peripheral glucose uptake in noninsulin-dependent diabetes mellitus. Metab. Clin. Exp. 37:15-22.

36. Consoli, A., N. Nurjhan, J. Reilly, D. Bier, and J. Gerich. 1990. Contribution of liver and skeletal muscle to alanine and lactate metabolism in man. Am. J. Physiol. 259:E677-E685. 